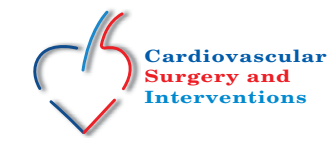

\title{
Endovascular treatment of penetrating aortic ulcer: A case report
}

\author{
Janko Pasternak ${ }^{1}$, Milos Kacanski ${ }^{1}$, Slavko Budinski ${ }^{1}$, Viktor Til ${ }^{2}$ \\ ${ }^{1}$ Department for Surgery, University of Novi Sad, Faculty of Medicine, Serbia, Yugoslavia \\ ${ }^{2}$ Department for Radiology, University of Novi Sad, Faculty of Medicine, Serbia, Yugoslavia
}

Received: July 19, 2018 Accepted: November 01, 2018 Published online: April 24, 2019

\section{ABSTRACT}

A 51-year-old male patient was admitted with a penetrating aortic ulcer. Endovascular aortic reconstruction was performed. The revascularization success was satisfactory, and the patient had no pain after the procedure. On control computed tomography angiography, the correct position and functionality of the endovascular stent graft was established without a penetrating ulcer of the aorta.

Keywords: Endovascular aneurysm repair, penetrating atherosclerotic ulcer, syndrome.

Penetrating aortic ulcer (PAU) is a disease which affects the aortic wall with aortic dissection and intramural aortic hematoma and forms the so-called acute aortic syndrome. Penetrating aortic ulcer accounts for about $7.5 \%$ of all cases of acute aortic syndrome. ${ }^{[1]}$

Penetrating aortic ulcer can be asymptomatic or symptomatic. In symptomatic cases, it presents with chest pain in the form of tearing, splitting, and pulsing, but it can also present with chronic back pain and misdiagnosed as lumbar syndrome. ${ }^{[2]}$

Diagnosis of PAU mainly depends on clinical presentation and morphology of the ulcer. It can be treated with conservative treatment with follow-up, open classical surgery and ulcer resection, or endovascular placement of the stent-graft to exclude the ulcer from the circulation. ${ }^{[3]}$

Herein, we report a successful case of endovascular treatment of PAU.

\section{CASE REPORT}

A 51-year-old male patient was admitted with PAU to the vascular surgery outpatient clinic. The diagnosis of PAU was made using Duplex ultrasonography and confirmed by computed tomography angiography (CTA) of the aortoiliac segment. His medical history revealed low back pain which was previously misdiagnosed as lumbar syndrome. The patient had also several comorbidities including nicotinism, hypertension, hyperlipoproteinemia, ischemic chronic cardiomyopathy with a left ventricular ejection fraction of only 35\%, chronic obstructive pulmonary disease, and non-significant stenosis of the internal carotid arteries bilaterally. The CTA (Siemens SOMATOM Sensation 16; Siemens Healthcare $\mathrm{GmbH}$, Erlangen, Germany) showed peripheral arterial occlusive disease with a PAU, $18 \mathrm{~mm}$ in diameter, located in the first lumbar vertebra (Figure 1).

A written informed consent was obtained from the patient. Stent grafting with endovascular aneurysm repair (EVAR) using Medtronic was performed at the Radiology Center under general endotracheal anesthesia. Endovascular procedure was performed satisfactory without local and systemic complications, and the procedure lasted for $100 \mathrm{~min}$. The patient was discharged in the postoperative third day with a good mobilization and reduced back pain. Control CTA which was performed at one and six months and at one year revealed a correct stent-graft position without thrombosis and stenosis within the lumen (Figure 2).

Corresponding author: Janko Pasternak, MD. Department for Surgery, University of Novi Sad, Faculty of Medicine, Serbia, Yugoslavia. Tel: +381648059798 e-mail: janko.pasternak@mf.uns.ac.rs

\section{Citation:}

Pasternak J, Kacanski M, Budinski S, Til V. Endovascular treatment of penetrating aortic ulcer: A case report. Cardiovasc Surg Int 2019;6(1):21-22. 


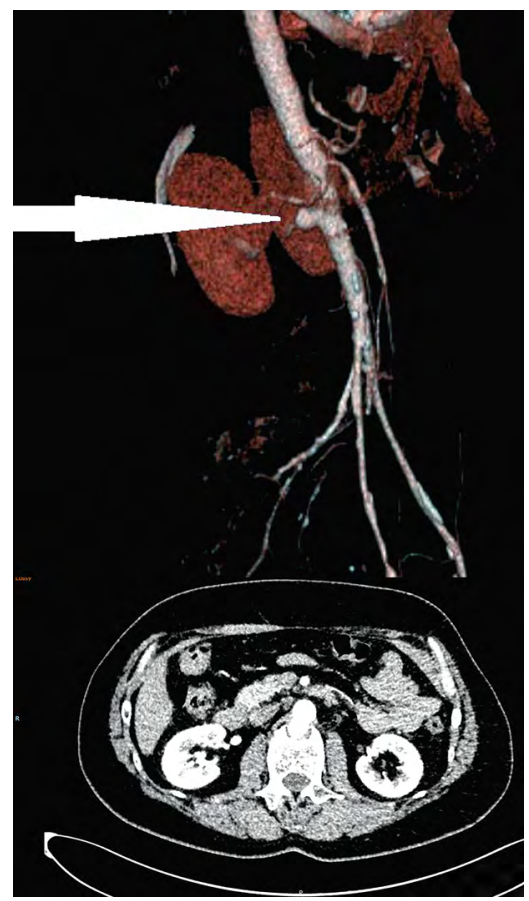

Figure 1. Computed tomography angiography confirming the diagnosis of penetrating aortic ulcer (white arrow).

\section{DISCUSSION}

Magnetic resonance angiography has been shown to be most useful method for PAU morphology and intramural hematoma and dissection. However, in symptomatic PAU cases, CTA is also indicated and, as in our case, it is a simple and more available method for a rapid diagnosis. ${ }^{[2]}$

The diameter of PAU in our case was $18 \mathrm{~mm}$. In the literature, larger diameters of PAU have been reported. Batt et al. $^{[3]}$ reported that the course of PAUs was very unpredictable and that the diameter and location of the ulcer did not have a significant effect, and a prompt treatment was needed, due to a high risk of rupture.

In our case, EVAR was performed under general endotracheal anesthesia. Lately, there has been an increase in the number of EVAR procedures under local anesthesia, and local anesthesia has been given priority for lower mortality and morbidity rates and shorter length of intensive care unit and hospital stay. ${ }^{[4]}$

The major early complication of EVAR is endoleak. On control CTA, endoleak was not seen in our

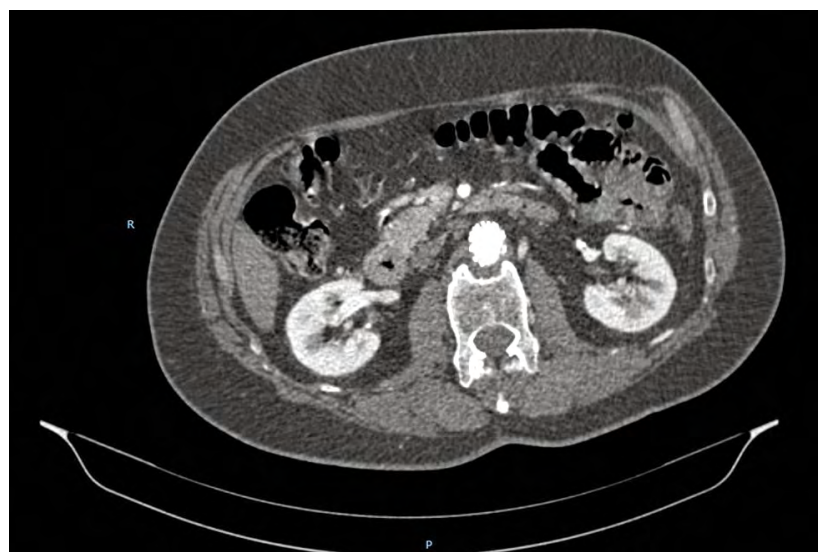

Figure 2. Abdominal computed tomography angiography showing correct stent-graft position at one year.

patient. In addition, intra- and postoperative EVARrelated complications include those arising from an femoral access, systemic complications, ischemic complications due to unintended embolization, stenosis, or stent graft occlusion. ${ }^{[3]}$ In our case, none of these complications were seen.

In conclusion, endovascular stent grafting for the treatment of penetrating aortic ulcer is a very successful treatment method with less complications and it is a good alternative to conventional open surgery in selected cases.

\section{Declaration of conflicting interests}

The authors declared no conflicts of interest with respect to the authorship and/or publication of this article.

\section{Funding}

The authors received no financial support for the research and/or authorship of this article.

\section{REFERENCES}

1. Harris JA, Bis KG, Glover JL, Bendick PJ, Shetty A, Brown OW. Penetrating atherosclerotic ulcers of the aorta. J Vasc Surg 1994;19:90-8.

2. Bischoff MS, Geisbüsch P, Peters AS, Hyhlik-Dürr A, Böckler D. Penetrating aortic ulcer: defining risks and therapeutic strategies. Herz 2011;36:498-504.

3. Batt M, Haudebourg P, Planchard PF, Ferrari E, HassenKhodja R, Bouillanne PJ. Penetrating atherosclerotic ulcers of the infrarenal aorta: life-threatening lesions. Eur J Vasc Endovasc Surg 2005;29:35-42.

4. Parra JR, Crabtree T, McLafferty RB, Ayerdi J, Gruneiro LA, Ramsey DE, et al. Anesthesia technique and outcomes of endovascular aneurysm repair. Ann Vasc Surg 2005;19:123-9. 